\title{
Elektromobilität. Quo vadis?
}

\section{J. Fabian OVE}

Online publiziert am 28. April 2015

(C) Springer Verlag Wien 2015

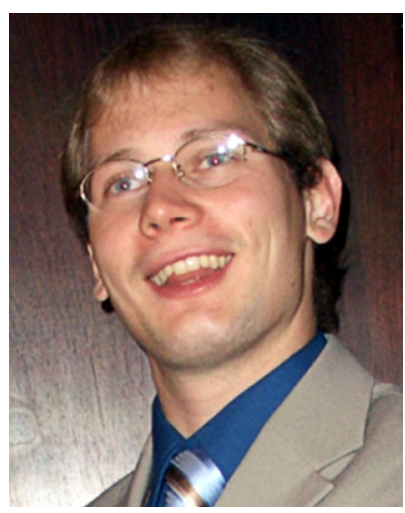

Dipl.-Ing. Dr. Jürgen Fabian
Die Elektromobilität zeigt großes Potential, die Bewegungsform der Zukunft zu werden: Die Vorteile sind hohe Energieeffizienz, Rückgewinnung der Bremsenergie (Rekuperation), geringe Treibhausgase und Schadstoffemissionen, beinahe Lärmfreiheit sowie niedrige Betriebskosten und geringe Abgaben. Dabei sind Elektrofahrzeuge durchaus keine Neuerfindung. Das erste Fahrzeug mit Elektroantrieb wurde

bereits 1881 bei der Weltausstellung in Paris von Gustave Trouvé vorgestellt. Schon um 1830, lange bevor Karl Benz den Verbrennungsmotor erfand, fuhren Elektroautos auf Europas Straßen. Es war auch das Elektroauto "La Jamais Contente", welches 1899 als erstes Fahrzeug der Welt die 100-km/h-Geschwindigkeitsgrenze durchbrach. Erst im Jahre 1912 begann mit der Erfindung des Elektrostarters der Siegeszug der benzin- und dieselbetriebenen Verbrennungskraftmotoren, mit all ihren Vor- und Nachteilen.

Nach einem fast 100-jährigen „Dornröschenschlaf" erhält das Thema Elektromobilität wieder neuen Schwung. Um die zukünftigen Mobilitätsbedürfnisse zu erfüllen, stehen die Automobilindustrie sowie die Energiewirtschaft heutzutage vor der epochalen Herausforderung der praxistauglichen Elektrifizierung des Fahrantriebs, welche die Wertschöpfungsketten und die Branchenstrukturen beider Industrien für die nächsten Jahrzehnte signifikant verändern wird. Durch die hohe Energieeffizienz und einen verstärkten Einsatz von erneuerbaren Energiequellen kann die Elektromobilität einerseits einen Beitrag zum Klima- und Umweltschutz leisten als auch anderseits zur Reduzierung der Importabhängigkeit fossiler Energieträger beitragen und stellt somit eine gemein- same Schnittmenge der Automobilindustrie und Energiewirtschaft dar.

Attraktive Elektromobilität erfordert grundlegend neue Ideen und Technologien, welche die Verringerung der verkehrsbedingten Probleme in Ballungsräumen unterstützen. Allerdings stellt diese Technologie keine Insellösung dar, sondern muss in Zusammenhang mit einem Bündel an Maßnahmen bewertet werden. Nur im Verbund mit dem Ausbau öffentlicher und privater Ladestationen, der Anpassung des elektrischen Versorgungssystems und der Bereitstellung neuer Mobilitätskonzepte kann die Elektromobilität einen nachhaltigen Beitrag zur Mobilität der Zukunft leisten.

Diese Ausgabe umfasst sieben Originalbeiträge mit unterschiedlichen und vielseitigen Aspekten der Elektromobilität: vom Entwicklungsprozess und der Analysemethodik mechatronischer Komponenten im Fahrzeug über automotive Software hin zur elektromagnetischen Verträglichkeit, dem Crashverhalten von Batterien, einer probabilistischen Methode zur Modellierung des Ladeverhaltens, einem innovativen Heizkonzept für Elektroautos bis hin zur Machbarkeitsanalyse einer rein elektrisch betriebenen Taxiflotte. Weitere drei Artikel in der Rubrik "praxis+wissen" beschäftigen sich mit batteriebetriebenen Bussen, einem von Studenten selbstgebauten ElektroRennauto und der Teilnahme an der österreichisch-ungarischen Elektro-Rallye „e-via”.

Die große inhaltliche Breite der Forschungsthemen lässt auf die Komplexität bei der Gestaltung der Mobilität der Zukunft schließen. Signifikante Veränderungen im Wertschöpfungsprozess können sich nur dann ergeben, sofern alle Beteiligten - Fahrzeugindustrie, Energieversorger, Öffentliche Hand, Gesetzgebung und natürlich die Nutzer selbst - zusammenarbeiten und gemeinsam Mobilitätsangebote entwickeln und anbieten. Nur ein effizientes Zusammenspiel aller Beteiligten wird auch in Zukunft unsere wachsenden Ballungsräume lebenswert gestalten.

Ich wünsche den Leserinnen und Lesern viele interessante Neuigkeiten und einen guten Einblick in die vielfältigen Lösungsansätze über die komplexen Herausforderungen, die heutzutage mit der Elektromobilität verbunden sind.

Fabian, Jürgen, Institut für Fahrzeugtechnik, Technische Universität Graz, Inffeldgasse 